\title{
The United Nations Political Declaration on Non- communicable Diseases: are countries of the Eastern Mediterranean Region ready to respond?
}

\author{
Ala Alwan ${ }^{1}$
}

Noncommunicable diseases (NCDs), mainly cardiovascular diseases, diabetes, cancers and chronic respiratory diseases, are the leading causes of death globally and in the World Health Organization's Eastern Mediterranean Region (WHO-EMR) [1]. These diseases have reached epidemic proportions, yet they could be significantly reduced, with millions of lives saved and untold suffering avoided, through prevention, early detection and timely treatment.

As the extent of NCDs increases, and as populations age, annual deaths from these diseases are projected to continue to rise worldwide; however, together with Africa, EMR is estimated to see the greatest increase [1]. NCDs kill at a younger age in developing countries including our Region where, in some countries, up to $50 \%$ of those who die from such diseases die below the age of 60 years, compared to less than $10 \%$ in Western Europe [1]. Morbidity, disability and premature death reduce productivity and have a serious negative impact on sustainable development. In poorer populations most health care costs must be paid directly out of pocket by patients; thus the cost of health care for patients with NCDs can be a significant burden on household budgets of lower income families and may drive them below the poverty line. Many countries of the Region have very high rates of out-of-pocket expenditure, reaching levels as high as $80 \%$ while nine countries have rates over 50\% [2].
A large proportion of NCDs can be prevented by reducing the four main risk factors: tobacco use, physical inactivity, unhealthy diet and the harmful use of alcohol [3]. Much of the disease Through implementation of the global strategy for the prevention and control of noncommunicable diseases and by adopting the tools to reduce the risk factors [4], much of the burden of NCDs and the human suffering they cause can be avoided. In that regard, the Political Declaration of the High-Level Meeting of the United Nations General Assembly on the Prevention and Control of Non-communicable Diseases, adopted by Heads of State and Government in September 2011, provides a road map for Member States to address the NCD epidemic [5]. Among the commitments made by governments was strengthening national action against NCDs in the three key components of the global strategy: surveillance, prevention and health care.

While our Region is increasingly recognizing the importance of NCDs as a leading health challenge, action has been generally slow and fragmented in many countries. National policies and plans for NCDs are often underdeveloped or non-operational. Engagement of key non-health sectors is weak in almost all countries. National institutional capacity is frequently inadequate and programmes are typically underfunded without clear budgetary allocations [6].

Major gaps exist in all three key component of the strategy [7]. All the countries have varying weaknesses in the three essential elements of the surveillance framework: a) motoring risk factors and determinants, b) monitoring outcomes, specifically mortality and morbidity, and c) monitoring health system capacity and response. Although most countries have conducted risk factors studies, surveys are not carried out at regular intervals, they are not institutionalized and the results are not necessarily linked with policy and programme development. Furthermore, the majority of the countries of the Region face considerable challenges in generating reliable cause-specific mortality rates for NCDs. In the area of prevention and control of risk factors, much work still needs to be done by countries to control the main risk factors. There are gaps in the adoption, implementation and enforcement of control policies and measures. This is reflected in persistently high rates of tobacco use, the unrestrained marketing of foods and non-alcoholic beverages to children and the high levels of salt and fat intake in many countries [7]. Lack of sufficient physical activity and overweight and obesity are also widely prevalent. As regards health care, efforts to integrate care for common conditions such as high blood pressure, diabetes and breast cancer into primary health care are still ongoing. At the same time, there are widespread inequities in access to health care that affect outcomes of NCDs, while several countries in the Region are experiencing acute or chronic humanitarian emergencies 
where access to care for NCDs is a major challenge.

All countries need to tackle the existing gaps and scale up action to combat NCDs. Multisectoral national policies and plans need to be developed and strengthened in partnership with key actors in non-health sectors. Top priorities include the implementation of cost-effective measures for tobacco control, diet and physical activity as well as action to control the promotion of unhealthy dietary patterns to children. Strengthening national systems for disease surveillance is also crucial in order to understand the current situation and monitor progress. Improved health care for people with NCDs requires action at all levels of the health system, although integration of priority interventions for NCDs at the primary health care level holds the greatest promise for impact and return on investment.
A three-year review of the progress made by Member States in implementing the commitments of the UN Political Declaration is scheduled for the last quarter of 2014 at the UN General Assembly. It is therefore imperative for Member States and WHO to plan ahead and work together with other regional and international partners both within and outside the health sector, in order to make the necessary progress and demonstrate a credible record of achievements in the prevention and control of NCDs in the Region.

In conclusion, the NCD epidemic exacts an enormous toll on this Region, in terms of disease burden, human suffering and human development. The response has not been commensurate with the magnitude and seriousness of the challenge. This must be redressed and committed, serious action taken by the countries; otherwise the burden of
NCDs will reach levels well beyond the capacity of countries and their international partners to manage.

An outline of the action needed by the countries of the Region was clearly articulated and endorsed during the 59th WHO Regional Committee for the Eastern Mediterranean in the strategic framework for action which covers the commitments of Member States to respond to the Political Declaration of the UN General Assembly on NCDs [8]. The framework provides a practical and evidence-based list of priority interventions to guide national authorities in responding to the NCD challenge in four areas: governance, surveillance, prevention and health care. If implemented, the framework provides an historic and unique opportunity for our Region to demonstrate leadership and take decisive action.

\section{References}

1. The Political Declaration of the United Nations General Assembly on the Prevention and Control of Non-Communicable Diseases: Commitments of Member States and the way forward. Technical Discussion paper, Fifty-ninth session of the Regional Committee for the Eastern Mediterranean, October 2012 (EM/RC59/3) (http://applications.emro.who.int/docs/RC_technical_papers_2012_3_14578_EN.pdf, accessed 30 September 2013).

2. Health systems strengthening in countries of the Eastern Mediterranean Region: challenges, priorities and options for future action. Technical Discussion paper, Fifty-ninth session of the Regional Committee for the Eastern Mediterranean, October 2012 (EM/RC59/Tech.Disc.1) (http://applications.emro.who. int/docs/RC_technical_papers_2012_Tech_Disc_1_14613_ EN.pdf, accessed 30 September 2013).

3. Global status report on noncommunicable diseases 2010. Geneva, World Health Organization, 2011 (http://whqlibdoc.who. int/publications/2011/9789240686458_eng.pdf, accessed 30 September, 2013).

4. Follow-up to the Political Declaration of the High-level Meeting of the General Assembly on the Prevention and Control of Non-communicable Diseases. Sixty-Sixth World Health Assembly, May 2013 (WHA66.10) (http://apps.who.int/gb/ ebwha/pdf_files/WHA66/A66_R10-en.pdf, accessed 30 September 2013).
5. Political Declaration of the High-level Meeting of the General Assembly on the Prevention and Control of Non-communicable Diseases. Sixty-sixth session of UN General Assembly, January 2012 (Resolution 66/2).

6. Assessing national capacity for the prevention and control of noncommunicable diseases: report of the 2010 global survey. Geneva, World Health Organization, 2012 (http://www.who. int/cancer/publications/national_capacity_prevention_ncds. pdf, accessed 30 September 2013).

7. Implementing the United Nations Political Declaration on Prevention and Control of Noncommunicable Diseases based on the regional framework for action (EM/RC60/9) (http://applications.emro.who.int/docs/RC_Techn_paper_2013_9_15001_EN.pdf, accessed 30 September 2013).

8. Framework for action to implement the United Nations Political Declaration on Noncommunicable Diseases: Annex to resolution $E M / R C 59 / R$.2. Fifty-ninth session of the Regional Committee for the Eastern Mediterranean, October 2012 (http://applications.emro.who.int/docs/RC_Resolutions_2012_2_Annex_14778_EN.pdf, accessed 30 September 2013). 